Revista Española de Derecho Internacional Sección PRÁCTICA ESPAÑOLA DE DERECHO INTERNACIONAL

Vol. 69/2, julio-diciembre 2017, Madrid, pp. 333-344 http://dx.doi.org/10.17103/redi.69.2.2017.3.01 (C) 2017 Asociación de Profesores de Derecho Internacional y Relaciones Internacionales ISSN: 0034-9380; E-ISSN: 2387-1253

\author{
III. PRÁCTICA ESPAÑOLA \\ DE DERECHO \\ INTERNACIONAL
}

\title{
EL TRIBUNAL CONSTITUCIONAL Y LA LEY CATALANA DE ACCIÓN EXTERIOR Y DE RELACIONES CON LA UNIÓN EUROPEA
}

\author{
Xavier Pons RaFOLS*
}

SUMARIO: 1. INTRODUCCIÓN.-2. LA STC 228/2016: ENTRE EL RECONOCIMIENTO CONSTITUCIONAL Y LA INCONSTITUCIONALIDAD PREVENTIVA.-2.1. La reiteración del reconocimiento constitucional de la acción exterior de Cataluña.-2.2. Las debilidades y contradicciones de la sentencia del Tribunal Constitucional.-2.2.1. La restrictiva concepción de la noción de diplomacia pública.-2.2.2. La restrictiva y anacrónica concepción de las relaciones institucionales con las oficinas consulares.-2.2.3. La regresión en la interpretación constitucional del denominado derecho a decidir--3. CONSIDERACIONES FINALES.

\section{INTRODUCCIÓN}

1. La reciente Sentencia del Tribunal Constitucional (TC) sobre la Ley catalana de acción exterior y de relaciones con la Unión Europea ${ }^{1}$ constituye un paso más en la consolidación de una jurisprudencia constitucional que ha venido avalando reiteradamente una acción exterior autonómica en el ejercicio de sus competencias. Entiendo, sin embargo, que el contexto político actual, con la deriva independentista del Gobierno de la Generalidad, ha condicionado en cierta medida la labor del TC, igual que condicionó, sin lugar a dudas, la adopción de la Ley catalana. Pese a lo cual, la Ley 16/2014, de 4 de diciembre ${ }^{2}$, es una ley autonómica de acción exterior - la primera en su género ciertamente- que resulta, a mi juicio, perfectamente plausible como desarrollo de las competencias que el Estatuto de Autonomía de Cataluña (EAC) atribuye a la Generalidad, tanto en materia de acción exterior como de relaciones con la Unión Europea.

2. En este sentido, creo que no debería haber problema alguno en un desarrollo legislativo autonómico de las competencias estatutarias en esta

\footnotetext{
* Catedrático de Derecho internacional público en la Universitat de Barcelona (xpons@ub.edu).

1 STC 228/2016, de 22 de diciembre.

2 Ley 16/2014, de 4 de diciembre, de acción exterior y de relaciones con la Unión Europea, BOE núm. 309, de 23 de diciembre de 2014 (en adelante, la Ley o Ley catalana).
} 
materia, tanto en Cataluña como en las otras Comunidades Autónomas cuyos Estatutos han reconocido competencias en este ámbito, apuntalando así una práctica abundantemente extendida. Lo que no es obstáculo para reconocer que la Ley catalana no es ni de lejos un prodigio de calidad legislativa, más bien al contrario, ya que evidencia una imprecisa técnica jurídica, con abundante e interesada utilización de conceptos confusos; acaba teniendo, en la práctica, poco contenido normativo; y, a los efectos que ahora interesan, desprende también un particular humus independentista, como contribución a la creación de lo que, en lenguaje soberanista, se han denominado estructuras de Estado.

3. Sobre este planteamiento, debo referirme, en primer lugar y de manera muy breve, al reconocimiento constitucional de la acción exterior autonómica, reiterado de nuevo en esta sentencia. Como es sabido, a partir de la STC 165/1994 se operó un cambio de tendencia jurisprudencial con el reconocimiento constitucional de las actividades con proyección exterior de las Comunidades Autónomas, en la medida que resultasen necesarias o convenientes para el ejercicio de sus competencias y con el límite de los elementos esenciales que configuran la competencia exclusiva del Estado ex art. 149.1.3 de la Constitución Española (CE) y que el propio TC identificaba, sin pretender por ello una descripción exhaustiva ${ }^{3}$. Este planteamiento ha sido repetido desde entonces en numerosas ocasiones y el TC lo reafirmó también en su sentencia sobre el $\mathrm{EAC}^{4}$. En esa sentencia, además de reiterar el reconocimiento de la proyección exterior de la Generalidad y fijar los límites y alcance de esta acción exterior autonómica, el TC, de un lado, subrayó el elemento esencial de que dentro de la competencia estatal se situaba también la posibilidad de establecer medidas que regulasen y coordinasen las actividades autonómicas de proyección exterior; y, de otro lado, avaló completamente las disposiciones estatutarias sobre la acción exterior y sobre las relaciones de la Generalidad con la Unión Europea que, en parte, habían sido objeto del recurso de inconstitucionalidad presentado por el Partido Popular ${ }^{5}$.

4. En la STC $46 / 2015^{6}$, sobre la Ley catalana del Síndic de Greuges ${ }^{7}$, el TC resumió la jurisprudencia anterior en un correcto intento de síntesis de la doctrina constitucional sobre las actividades de las Comunidades Autónomas con proyección en el exterior y el alcance de la competencia estatal; síntesis que ha sido reiterada más recientemente en la STC $85 / 2016^{8}$ y en la sentencia que

3 STC 165/1994, de 26 de mayo, FFJJ 3, 4 y 5.

4 STC 31/2010, de 28 de junio, FJ 125.

5 Véanse los comentarios en esta esfera de OlEsti Rayo, A., «Las relaciones de la Generalidad con la Unión Europea», Revista Catalana de Dret Públic. Especial Sentencia 31/2010 del Tribunal Constitucional, sobre el Estatuto de Autonomía de Cataluña de 2006, 2010, pp. 409-413 y PoNs RAFOLs, X., «La acción exterior de la Generalidad en la sentencia del Tribunal Constitucional sobre el Estatuto de autonomía de Cataluña», en ibid., pp. 414-420.

6 STC 46/2015, de 5 de marzo, FJ 4.

7 Ley 24/2009, de 23 de diciembre, del Síndic de Greuges, BOE núm. 15, de 18 de enero de 2010.

8 STC 85/2016, de 28 de abril, FJ 3. 
ahora me ocupa ${ }^{9}$. La cuestión está, por tanto, plenamente consolidada en la jurisprudencia constitucional y es reconocida pacíficamente por la doctrina ${ }^{10}$.

5. En segundo lugar, debe apuntarse que el inmenso vacío legal existente en materia de acción exterior estatal fue cubierto finalmente con la adopción de la Ley $2 / 2014$, de 25 de marzo, de la acción y del servicio exterior del Estado $^{11}$, y de la Ley 25/2014, de 27 de noviembre, de tratados y otros acuerdos internacionales ${ }^{12}$, ambas relevantes también por lo que se refiere a la acción exterior autonómica ${ }^{13}$. De manera especial, en la Ley de la acción y del servicio exterior del Estado, además de formularse una distinción artificiosa y confusa entre «política exterior» y «acción exterior» — que solo aparentaba, a mi entender, querer negar a las Comunidades Autónomas la capacidad de llevar a cabo una acción exterior con «dimensión política»—, se ubica en una expresa disposición normativa la esencia de la doctrina constitucional sobre el alcance de la proyección exterior autonómica, se faculta al Gobierno del Estado para fijar las medidas y directrices que regulen y coordinen las actividades en el exterior de las Comunidades Autónomas, y se establecen diversas obligaciones de información previa sobre, por ejemplo, determinados viajes o el establecimiento de oficinas en el exterior ${ }^{14}$.

6. El Gobierno de la Generalidad se planteó recurrir esta ley y solicitó el preceptivo dictamen del Consejo de Garantías Estatutarias quien, sin embargo, avaló la constitucionalidad de la norma estatal en la medida en que, aunque detectó un evidente humus fiscalizador de las competencias autonómicas, no cabía formular consideraciones de constitucionalidad de carácter preventivo ${ }^{15}$. Quien sí formuló recurso de inconstitucionalidad fue el Gobierno de Canarias, pero la ya citada STC 85/2016 rechazó las tachas de inconstitucionalidad planteadas con el argumento central de que las disposiciones

9 STC 228/2016, de 22 de diciembre, FJ 2.

${ }_{10}$ Una doctrina muy extensa y que se remonta a los años inmediatamente posteriores a la adopción de la CE. Solo a los efectos de que contextualizan este comentario me permito citar a Pons RAfols, X., Campins Eritja, M., Castellà Andreu, J. M. y Martín Núñez, E., La acción exterior y europea de la Generalidad de Cataluña. Desarrollo normativo e institucional, Madrid, Marcial Pons, CEI Tribuna Internacional, 2012; así como Pons RAfOLS, X., «La acción exterior de la Generalidad, los recientes desarrollos legislativos estatales y la nueva Ley catalana de acción exterior y de relaciones con la Unión Europea», en Acción exterior y Comunidades Autónomas: Seminario, Barcelona, 1 de julio de 2014, Barcelona, Generalitat de Catalunya, Institut d'Estudis Autonòmics, 2015, pp. 45-125.

11 Ley 2/2014, de 25 de marzo, de la Acción y del Servicio Exterior del Estado, BOE núm. 74, de 26 de marzo de 2014.

12 Ley 25/2014, de 27 de noviembre, de Tratados y otros Acuerdos Internacionales, BOE núm. 288, de 28 de noviembre de 2014

13 Baste señalar aquí que la Ley de tratados y otros acuerdos internacionales reconoce que las Comunidades Autónomas pueden celebrar acuerdos internacionales administrativos y acuerdos internacionales no normativos. Véanse, en general, los distintos estudios de MARTín y Pérez DE NANCLAREs, J. en ANdrés Sáenz de Santamaría, P., Díez-Hochleitner Rodríguez, J. y Martín y Pérez de Nanclares, J. (dirs.), Comentarios a la Ley de tratados y otros acuerdos internacionales, Madrid, Civitas/Thomson Reuters, 2015.

${ }_{14}$ Véase, al respecto, el estudio de García PéREZ, R., «La proyección internacional de las Comunidades Autónomas en la Ley de la Acción y del Servicio Exterior del Estado (LASEE): Autonomía territorial y unidad de acción de la política exterior», Revista Electrónica de Estudios Internacionales, vol. 27, 2014, pp. 1-30.

15 Dictamen 14/2014, de 17 de junio, del Consejo de Garantías Estatutarias. 
cuestionadas eran, en gran medida, la expresión de las facultades de coordinación y ordenación de la política exterior que corresponden al Gobierno al amparo del art. 149.1.3 $\mathrm{CE}^{16}$.

7. Por su parte, el Parlamento catalán adoptó la Ley de acción exterior y de relaciones con la Unión Europea que, a mi entender, como he dicho, resulta una ley conveniente y necesaria para ordenar y regular la acción exterior y europea que realiza la Generalidad, aunque no creo que su estructura y contenido sean los más adecuados, ya que estimo que resulta muy débil su calidad legislativa y me parece que apenas aporta valor añadido en términos jurídico-normativos ${ }^{17}$. Una vez adoptada la Ley catalana, el Gobierno impugnó sus arts. 1 a 9, 26 y 29 a 38 por considerar que invadían la competencia exclusiva del Estado en materia de relaciones internacionales. La impugnación se formuló sobre la base del art. 161.2 CE y, por consiguiente, al admitirse a trámite el recurso, se ordenó también la suspensión de los preceptos impugnados ${ }^{18}$. De conformidad también con lo dispuesto en este artículo, en el plazo de cinco meses el TC acordó mantener la suspensión de algunas de las disposiciones recurridas pero la levantó respecto de otras ${ }^{19}$. Finalmente, el 22 de diciembre de 2016, el TC dictó su Sentencia 228/2016 por la que declaró la inconstitucionalidad de determinadas disposiciones de la Ley catalana y formuló una interpretación conforme a la Constitución de otras tantas.

\section{LA STC 228/2016: ENTRE EL RECONOCIMIENTO CONSTITUCIONAL Y LA INCONSTITUCIONALIDAD PREVENTIVA}

8. La sentencia, aun avalando de nuevo, en términos generales, la acción exterior autonómica, expresó, de una manera a mi entender poco sólida y solvente en términos jurídicos, ciertas reservas y un evidente carácter preventivo declarando inconstitucionales algunas disposiciones de la ley, lo que casa difícilmente con lo que debería ser, estrictamente, un juicio de constitucionalidad.

\subsection{La reiteración del reconocimiento constitucional de la acción exterior de Cataluña}

9. Diversos fundamentos jurídicos de la STC 228/2016 avalaban la acción exterior autonómica, vinculándola siempre a las competencias autonó-

16 STC 85/2016, de 28 de abril, FJ 2. Consideración criticada en su voto particular por el Magistrado Juan Antonio Xiol Ríos, con la adhesión del Magistrado Fernando Valdés Dal-Ré, al estimar que el TC avalaba una competencia genérica de coordinación que no prevé la Constitución ni se había reconocido anteriormente por la jurisprudencia constitucional.

17 Véase un análisis de la Ley en Pons RAFOLs, X., op. cit., nota 10, pp. 45-125, en especial pp. 85-103.

18 Providencia de 14 de abril de 2015.

19 Auto 122/2015, de 7 de julio. 
micas y con los límites de las competencias estatales. Así, aunque en diversas disposiciones de la Ley catalana se formula una confusión interesada entre la «acción exterior de Cataluña» ${ }^{20}$ y lo que corresponde estrictamente, en sentido propio y de conformidad con el EAC, con la «acción exterior de la Generalidad», siendo Cataluña la Comunidad Autónoma y siendo la Generalidad - de conformidad con los arts. 1 y 2 del EAC - el sistema institucional en que se organiza su autogobierno, no debería haber ningún inconveniente, como indicó el TC, en vincular a Cataluña con el ejercicio de la acción exterior que, lógicamente, llevarán a cabo sus instituciones. Lo que se asociaba también con la idea de los «intereses de Cataluña» que también se mencionan en la Ley catalana ${ }^{21}$, ya que el TC ha vinculado reiteradamente la noción de «intereses» de una Comunidad Autónoma con la noción de "competencias», «al enmarcar aquellos las competencias y definir estas, a su vez, los intereses» ${ }^{22}$. Es decir, que la acción exterior de Cataluña en tanto ente territorial no podía significar en ningún caso la consideración de Cataluña como sujeto de Derecho internacional ${ }^{23}$. A mayor abundamiento, y aunque la ley se refiere en diversas ocasiones a Cataluña "como actor internacional activo» ${ }^{24}$, el TC consideró que aunque solo el Estado puede relacionarse en el exterior como sujeto de Derecho internacional nada impide que las Comunidades Autónomas «puedan presentarse como actores internacionales, estando esas entidades territoriales facultadas en determinados casos para realizar actuaciones en el ámbito exterior actuando siempre en el marco de las competencias propias de las Comunidades Autónomas» ${ }^{25}$. En consecuencia, la consideración de Cataluña como un actor internacional activo no podía ser entendida tampoco como una atribución de subjetividad internacional.

10. El TC también avaló, como no podía ser de otro modo, los arts. 2.d) y 7.2.e) de la Ley en relación con los acuerdos de colaboración ya que, por un lado, el art. 195 EAC autoriza a la Generalidad a suscribirlos «para la promoción de los intereses de Cataluña» en el «ámbito de sus competencias»; y, por otro lado, porque estos acuerdos de colaboración no son tratados internacionales, tal como los define y prescribe la nueva Ley de tratados y otros acuerdos internacionales. El reconocimiento del TC abarcaba también el art. 3 de la Ley catalana — salvo lo que luego indicaré en relación con el apdo.e) — que establece los principios rectores de la acción exterior y que tiene un claro contenido genérico y programático, del que no podía resultar un condicionamiento de la política exterior del Estado ${ }^{26}$.

11. Por último, el TC rechazó las tachas de inconstitucionalidad a los arts. 5 a 9 de la Ley, que enumeran las funciones de las instituciones catalanas

20 En la misma definición de la acción exterior en el art. 1 y en el art. 4.b) de la Ley.

21 En diversas disposiciones de la Ley: arts. 1, 2, 4, 8, 19, 21, 29, 31 y 32.

22 STC 31/2010, de 28 de junio, FJ 118.

23 STC 228/2016, de 22 de diciembre, FJ 4.

24 Art. 1.1.b) de la Ley. El art. 4.a) se refiere a Cataluña «como un actor internacional comprometido, solidario y responsable».

25 STC 228/2016, de 22 de diciembre, FJ 4.

${ }^{26}$ Ibid., FJ 6. 
en este ámbito de la acción exterior y de las relaciones con la Unión Europea porque, de un lado, estas disposiciones debían ser siempre entendidas como desarrollo de disposiciones estatutarias plenamente conformes con la $\mathrm{CE}$ y, de otro lado, porque, de nuevo, las acciones con proyección exterior de la Generalidad habían de circunscribirse en todo caso al ámbito de competencias de la Comunidad Autónoma de Cataluña ${ }^{27}$. En este mismo sentido, el TC rechazó las impugnaciones de los arts. 29 a 33 de la Ley, que desarrollan la representación de la Generalidad en el exterior, reconociendo así la legitimidad constitucional del establecimiento de oficinas autonómicas, ya sea ante la Unión Europea o, de manera general, para la promoción de los intereses de Cataluña - como también reconocen los arts. 192 y 194 del EAC—, sin invadir por ello los límites del ius legationis que corresponde al Estado ${ }^{28}$.

\subsection{Las debilidades y contradicciones de la sentencia del Tribunal Constitucional}

12. Si hay, por tanto, una parte de la sentencia que, en una concepción abierta, rechaza los argumentos poco solventes del recurso de inconstitucionalidad, aunque sea insistiendo reiteradamente en los límites competenciales, cuando el TC no formula interpretaciones conformes a la CE y declara la inconstitucionalidad de determinadas disposiciones de la Ley catalana evidencia, a mi entender, excesivas desconfianzas y profundas debilidades.

\subsubsection{La restrictiva concepción de la noción de diplomacia pública}

13. El TC, aunque convalidó la consideración de Cataluña como actor internacional, consideró inconstitucionales las definiciones contenidas en diversos apartados del art. 2 de la Ley referidas a la diplomacia pública, la misma expresión «Diplomacia pública de Cataluña» que rubrica el Capítulo I del Título IV de la Ley y el art. 38, que regula esta diplomacia pública ${ }^{29}$. Por «diplomacia pública», noción ciertamente confusa ${ }^{30}$, puede entenderse el conjunto de contactos formales e informales, permanentes o ad hoc con entidades extranjeras, públicas o privadas, con el propósito de promover asuntos de carácter socioeconómicos, políticos o culturales, así como cualquier otra dimensión externa de sus competencias que lleva a cabo una entidad subestatal $^{31}$. A juicio del TC, sin embargo, la diplomacia pública se «configura como

27 Ibid., FJ 8.

28 Ibid., FJ 10.

${ }^{29}$ No entro a considerarlo, pero me parece muy discutible que el TC declare la inconstitucionalidad de unas definiciones y de la expresión que constituye la rúbrica de un Capítulo de la Ley.

${ }^{30}$ Véase Vilariño Pintos, E., Curso de Derecho Diplomático y Consular, Madrid, 5. a ed., Tecnos, 2016, p. 80.

31 Véase, por ejemplo, Cornago Prieto, N., «Diplomacia, paradiplomacia y redefinición de la seguridad mundial: dimensiones de conflicto y cooperación», en KEATING, M. y ALdECOA, F. (coords.), Paradiplomacia: las relaciones internacionales de las regiones, Madrid, Marcial Pons, 2001, pp. 55-78. 
un conjunto de actuaciones con incidencia exterior, no vinculadas al ejercicio de competencias autonómicas, que dirige y coordina la Generalidad y cuyos destinatarios pueden perfectamente ser los Estados u organizaciones internacionales como sujetos de Derecho internacional, a tenor de las finalidades que persigue» ${ }^{32}$.

14. La clave argumental del TC residía en esta doble consideración de que con el concepto de diplomacia pública se configuraba una actuación exterior de la Generalidad «no vinculada al ejercicio de competencias autonómicas» -lo que, en cualquier caso, se plantee apodícticamente, puesto que no se justifica- y que los destinatarios de estas actuaciones "pueden perfectamente ser» sujetos de Derecho internacional —lo que, en todo caso, no es más que una mera posibilidad y no una consecuencia segura de la norma en cuestión - ${ }^{33}$. Además de estas debilidades argumentales, creo que se trata de una percepción que resulta contradictoria con lo afirmado en otros fundamentos de la misma sentencia sobre la relación entre intereses y competencias y, especialmente, sobre la interpretación conforme con la CE de aceptar la consideración de Cataluña como actor internacional.

15. Asimismo, con una visión errónea de las relaciones internacionales contemporáneas, el TC formuló una identificación de la diplomacia pública con las «relaciones diplomáticas», reservadas en exclusiva, ex art. 149.1.3 $\mathrm{CE}$, al Estado. Se trata de una identificación absolutamente inconsistente, como era inconsistente la consideración del Consejo de Estado cuando venía a entender que la "diplomacia pública» es un concepto inexistente porque la única diplomacia existente es aquella «real» que reconoce el Derecho internacional ${ }^{34}$. No hay ninguna duda de que las relaciones diplomáticas son entre Estados, pero de ahí a considerar que es inconstitucional la noción «diplomacia pública», concepto que, como el de la "paradiplomacia» o el de «actor internacional», están plenamente consolidados en las relaciones internacionales contemporáneas ${ }^{35}$, me parece un exceso sin demasiado sentido por parte tanto del Consejo de Estado como del TC y es expresión, además, de un preocupante desconocimiento de la dinámica actual de las relaciones internacionales. A mi juicio, no hay duda que la diplomacia pública existe y que se trata de algo conceptualmente distinto de las relaciones diplomáticas entre Estados. Es más, es lo que, con absoluta normalidad, han estado haciendo las Comunidades Autónomas desde hace mucho tiempo.

16. Cuestión distinta es que se hayan utilizado estos mecanismos para la internacionalización del proceso político soberanista. Creo que aquí el TC ha caído en su propia trampa preventiva y, como indicaba el Magistrado Juan

32 STC 228/2016, de 22 de diciembre, FJ 11.

33 Ambos aspectos son criticados por la Magistrada Adela Asúa Batarrita en su voto particular, al que se sumó el Magistrado Fernando Valdés Dal-Re.

34 Véase el Dictamen 173/2015, de 4 de marzo.

35 Como señala el Magistrado Juan Antonio Xiol Ríos en su voto particular, la Ley catalana parece estar refiriéndose al «fenómeno de la paradiplomacia global, noción extendida y de uso común en la teoría de las relaciones internacionales». 
Antonio Xiol Ríos en su voto particular, debía haber dejado «a un lado la sospecha del uso inconstitucional que la Comunidad Autónoma de Catalunya pueda hacer de las previsiones contenidas en su Ley de acción exterior». Entiendo, en este sentido, que siempre que haya una acción que pueda ser considerada ilegal o inconstitucional podrá impugnarse ante la jurisdicción competente, pero las disposiciones de una ley o su alcance normativo no pueden en ningún caso ser inconstitucionales solo por la prevención de que en el futuro se pudiese derivar de ellas una acción ilegal. A fin de cuentas, aunque se hayan anulado las definiciones, el art. 38 de la Ley y la expresión que rubrica el Capítulo en cuestión, las instituciones catalanas, públicas y privadas - entre ellas el Consejo de la Diplomacia Pública de Cataluña, que continúa existiendo ${ }^{36}$ - , seguirán llevando a cabo sus actividades de diplomacia pública ${ }^{37}$.

\subsubsection{La restrictiva y anacrónica concepción de las relaciones institucionales con las oficinas consulares}

17. El Gobierno también impugnó, de manera general, el art. 26 de la Ley por referirse a las relaciones del Gobierno de la Generalidad con otros Gobiernos y, particularmente, su apartado 1.e) que establece como objetivo de la Generalidad el de crear «relaciones institucionales fluidas y constantes con el cuerpo consular presente en Cataluña, en especial con las legaciones de países que tengan fuertes intereses y vínculos socio-económicos y culturales con Cataluña, y promover la creación de nuevos consulados de otros países, como una forma de potenciar las relaciones bilaterales con territorios que puedan tener interés en Cataluña». A mi entender, el objetivo de establecer unas relaciones institucionales fluidas y constantes con el cuerpo consular presente en Cataluña y promover el establecimiento de nuevos consulados no constituye - como en tantas otras ocasiones sucede en esta ley- más que la mera expresión de aspiraciones. Por lo que se refiere a la primera parte de la frase, puede entenderse, además, como algo habitual y normal que, probablemente, otros tipos de entidades públicas o privadas intentarán también mantener en su actividad cotidiana con los consulados extranjeros ubicados en su ámbito territorial ${ }^{38}$. Por lo que se refiere a la segunda parte de la frase, no es más que una mera retórica voluntariosa para que se establezcan nuevos

\footnotetext{
36 Creado por Decreto 149/2012, de 20 de noviembre, de modificación de los Estatutos y de la denominación del Patronat Catalunya Món, que se convierte en Patronat Catalunya Món - Consell de Diplomàcia Pública de Catalunya (PCM - DIPLOCAT), DOGC núm. 6259, de 22 de noviembre de 2012, y cuyos objetivos se concretan en "convertirse en un instrumento del Gobierno para desarrollar una estrategia de diplomacia pública y contribuir al conocimiento y reconocimiento exterior del país».

37 Que, en esencia, deberían consistir, a mi juicio, en el fortalecimiento y coordinación de la acción exterior y europea de la Generalidad en un escenario internacional donde son más intensas que nunca las conexiones internacionales de todo tipo, favoreciendo, así, el desarrollo, el progreso económico y social y la internacionalización de la economía catalana.

38 De ahí que el mismo TC no advirtiera que este art. 26 pudiera ocasionar perjuicios para la dirección y ejecución de la política exterior del Estado, lo que justificó el levantamiento de la suspensión de este precepto (Auto 122/2015, de 7 de julio, FJ 6).
} 
consulados, algo que, como es evidente, depende solo y exclusivamente de la recíproca voluntad del Estado que envía y del Estado receptor - y no de la Generalidad-, de conformidad con la Convención de Viena sobre relaciones consulares.

18. El TC, que no admitió las tachas de inconstitucionalidad generales sobre los objetivos establecidos en el art. 26 de la Ley catalana, sí admitió, de una manera poco sólida a mi juicio, la impugnación contra el apartado 1.e) de este art. 26. El TC consideró que la referencia a la promoción por la Generalidad del establecimiento de consulados de otros países «como una forma de potenciar las relaciones bilaterales» propiciaba la asunción de una función representativa a nivel internacional que no le correspondía, por ser propia del Estado. Además, el TC estimó que potenciar estas relaciones bilaterales «puede suponer un condicionamiento o menoscabo para la política exterior del Estado español». Creo que podía haberse formulado perfectamente una interpretación conforme con la $\mathrm{CE}$ de esta disposición considerando que estas relaciones bilaterales a través de las oficinas consulares presentes en Cataluña pueden ser de carácter cultural, económico o social y en el marco de las competencias de la Generalidad y, por tanto, no tienen por que provocar condicionamiento alguno para la política exterior del Estado. Porque, en definitiva, no son, en ningún caso, relaciones consulares, sino tan solo «relaciones institucionales con cuerpos consulares foráneos» ${ }^{39}$.

19. Débil es también el argumento principal que utiliza el TC para declarar la inconstitucionalidad de este apartado, estimando que esta disposición «viene a equiparar el cuerpo consular, categoría recogida en el Convenio de Viena de 1963, con el concepto de "legación", que es un tipo de representación diplomática (dirigida por un ministro o encargado de negocios, no por un embajador), estableciendo que el Gobierno de la Generalidad de Cataluña mantendrá relaciones con el cuerpo consular y con legaciones (diplomáticas), lo que contraviene la reserva ex art. 149.1.3 CE a favor del Estado en relación con el ius legationis» ${ }^{40}$. Creo que el TC incurre aquí en desconocimiento del Derecho internacional cuando se refiere confusamente al «cuerpo consular» o al concepto de «legación». El primer concepto simplemente no existe en el Convenio de Viena de 1963 sobre relaciones consulares ${ }^{41}$, más allá de usarse comúnmente, como hace la Ley catalana, para referirse al conjunto de los agentes consultares acreditados en un Estado, en este caso España y presentes en Cataluña o aplicarse a las placas de los vehículos al servicio de las oficinas consulares; y el segundo es un concepto que evoca categorías históricas del Derecho diplomático, que ya no están siquiera recogidas en el Convenio de Viena de 1961 sobre relaciones diplomáticas ${ }^{42}$. Parece más bien

\footnotetext{
39 Literalmente así lo subraya el voto particular del Magistrado Juan Antonio Xiol Ríos.

40 STC 228/2016, de 22 de diciembre, FJ 9.

41 Convenio de Viena sobre Relaciones Consulares de 24 de abril de 1963, BOE núm. 56, de 6 de marzo de 1970 .

42 Convenio sobre Relaciones Diplomáticas firmado en Viena el día 18 de abril de 1961, BOE núm. 21, de 24 de enero de 1968. Véase Vilariño PinTos, E., op. cit., nota 30, p. 182.
} 
que el TC se quedó, anacrónicamente, en un aspecto meramente formal y de carácter histórico, utilizando expresiones y conceptos incorrectos o completamente desfasados. En todo caso, entiendo que el concepto «legación», que es el que emplea - de manera ligera, ciertamente- la Ley catalana, se puede utilizar, aunque técnicamente no sea lo correcto, para referirse de manera genérica tanto a las misiones diplomáticas como a las oficinas consulares y en este sentido, en el contexto sistemático de la disposición en cuestión, se refería simplemente a las oficinas consulares ubicadas en Cataluña.

\subsubsection{La regresión en la interpretación constitucional del denominado derecho a decidir}

20. Aunque resulta más tangencial sobre lo que constituye el núcleo central de la acción exterior autonómica y de la misma sentencia que me ocupa, resulta también conveniente referirse a la declaración de inconstitucionalidad que el TC formuló en relación con el art. 3.e) de la Ley catalana que, en el contexto de la fijación de los principios rectores de la acción exterior, se refería al «reconocimiento del derecho a decidir de los pueblos». Resulta obvio, a mi juicio, que se trataba de una disposición que pretendía el efecto político que no jurídico- de referirse en un texto legal al denominado derecho a decidir. El TC declaró la inconstitucionalidad de esta disposición por considerar que el «inciso en cuestión viene a habilitar a la Generalidad de Cataluña para apoyar procesos de independencia en otros Estados, lo que en modo alguno tiene acomodo en las facultades que le corresponden a la Generalidad en su acción exterior» y que la Generalidad «carece de competencia para llevar a cabo el reconocimiento del derecho a la autodeterminación o a la soberanía de pueblo alguno, por cuanto este tipo de reconocimientos solo corresponde al Estado español como sujeto de Derecho internacional público» ${ }^{43}$.

21. Obviamente, el TC estaba plenamente en lo cierto en relación con las competencias en materia de acción exterior que han de estar necesariamente relacionadas con la promoción de los intereses autonómicos, deben llevarse a cabo mediante el ejercicio de acciones con proyección exterior que se deriven directamente de sus competencias y deben respetar el límite de la competencia estatal exclusiva en materia de política internacional y de relaciones exteriores. Lo que resulta, a mi juicio, reprobable del planteamiento del TC es la identificación que se formulaba entre el denominado derecho a decidir y el derecho a la autodeterminación o a la soberanía de un pueblo. En términos jurídicos - que no políticos- esta identificación no es cierta en ningún caso, entre otras cosas porque este pretendido derecho a decidir no existe como tal derecho, ni en el Derecho interno ni en el Derecho internacional. Pero lo más criticable es que este planteamiento del TC resultaba plenamente contradictorio con su propia consideración sobre el denominado derecho a decidir, que expresó con acertada y meridiana claridad en su STC 42/2014,

\footnotetext{
43 STC 228/2016, de 22 de diciembre, FJ 6.
} 
de 25 de marzo, sobre la Declaración de soberanía y del derecho a decidir del pueblo de Cataluña. En aquella ocasión, el TC estimó que algunos de los principios de la Declaración adoptada por el parlamento autonómico podían ser adecuados a la CE ya que daban cauce «a la interpretación de que el "derecho a decidir de los ciudadanos de Cataluña" no aparece proclamado como una manifestación de un derecho a la autodeterminación no reconocido en la Constitución, o como una atribución de soberanía no reconocida en ella, sino como una aspiración política a la que solo puede llegarse mediante un proceso ajustado a la legalidad constitucional con respeto a los principios de "legitimidad democrática", "pluralismo", y "legalidad", expresamente proclamados en la Declaración en estrecha relación con el "derecho a decidir" ${ }^{44}$.

22. Es decir, el TC formulaba entonces una interpretación conforme con la $\mathrm{CE}$ del denominado derecho a decidir, y reiteraba que en una sociedad democrática como la española todas las posiciones políticas eran posibles y podían ser defendidas, siempre que su defensa no se llevase a cabo mediante «una actividad que vulnere los principios democráticos, los derechos fundamentales o el resto de los mandatos constitucionales, y el intento de su consecución efectiva se realice en el marco de los procedimientos de reforma de la Constitución, pues el respeto a esos procedimientos es, siempre y en todo caso, inexcusable» ${ }^{45}$. De manera parecida, en el ya citado Auto 122/2015, por el que se declaraba el levantamiento de la suspensión de algunas de las disposiciones de la Ley catalana, el TC levantó la suspensión de este inciso precisamente porque - entonces sí- recordó que cabía una interpretación constitucional de la referencia al «derecho a decidir» ${ }^{46}$. En este sentido, entiendo que no es de recibo que el TC caiga en el efecto tramposo de las consideraciones políticas, obviando su verdadera función jurídico-constitucional que tan claramente había expresado en su STC 42/2014 cuando, al formular esta interpretación conforme con la $\mathrm{CE}$ de los principios asociados al denominado derecho a decidir, daba plena cabida a cualesquiera acuerdos políticos en el marco constitucional que pudieran resultar adecuados para resolver la crisis político-territorial que ha generado el proceso soberanista en Cataluña.

\section{CONSIDERACIONES FINALES}

23. Pese a que el contexto político del momento pueda explicar el $h u$ mus independentista de la Ley catalana e, incluso, el poco fundamentado y excesivo carácter preventivo de las alegaciones del Gobierno, creo que en esta ocasión el TC no ha estado a la altura de sus responsabilidades como jurisdicción constitucional. Aunque la ley, como ya he dicho, es más bien mala, la STC 228/2016 que me ha ocupado resulta, también, a mi juicio, más bien pobre. Reitera, en parte, el reconocimiento constitucional de la acción

\footnotetext{
44 STC 42/2014, de 25 de marzo, FJ 3.

45 Ibid., FJ 4.

46 Auto 122/2015, de 7 de julio, FJ 5.
} 
exterior autonómica, insistiendo en la fundamentación de esta proyección exterior en las competencias autonómicas, algo ya sabido y que no aporta mayor valor añadido; y en parte, con fundamentos jurídicos poco sólidos y solventes, contradictorios con su propia jurisprudencia y con desconocimiento de algunas de las realidades actuales del Derecho internacional y de las relaciones internacionales contemporáneas, expresa reticencias políticas y un excesivo humus de carácter preventivo. Lo que no concuerda con lo que debería ser, propiamente, un juicio de constitucionalidad.

24. Como el propio TC ha dicho en otras ocasiones, como jurisdicción constitucional no le corresponde pronunciarse sobre eventuales o hipotéticas interpretaciones y, en este sentido, no proceden pronunciamientos preventivos a través de los cuales se pretenda evitar una posible y no producida aplicación de determinados preceptos en contradicción con la CE. Si esto se produjera, es decir, si la aplicación de la norma produce - y no solo que pueda producir - vulneración de la $\mathrm{CE}$, el ordenamiento jurídico ofrece otros cauces, ante la jurisdicción ordinaria o ante el mismo TC, para evitar que tales situaciones se produzcan. Entiendo, así, que no cabe pronunciarse sobre meras eventualidades, que es lo que acaba haciendo el TC en esta sentencia. Es decir, impugnación preventiva y sentencia preventiva también, ambas reprobables, como es reprobable la escasa calidad técnico-normativa de la Ley catalana y su alta imprecisión y poco valor normativo. Pero de la imprecisión y del humus que desprende la Ley catalana no debía derivarse necesariamente un pronunciamiento de inconstitucionalidad como el que se comenta, que tiene, a mi juicio, un claro carácter preventivo.

25. La acción exterior de las Comunidades Autónomas se fundamenta en la autonomía política que la CE les reconoce y garantiza, y ello, obviamente, puede generar conflictos políticos y jurídicos en materia de acción exterior que deriven del ejercicio de las competencias de las Comunidades Autónomas y de las del Estado. Solo la mutua lealtad institucional y el respeto de la distribución competencial en un Estado de estructura compuesta podrán facilitar la relación entre las distintas Administraciones, y podrán permitir solventar los problemas políticos y jurídicos que necesariamente se presentarán. En consecuencia, sobre la base del diálogo, la negociación y los acuerdos que resulten necesarios para definir la acción exterior del Estado y resolver los conflictos políticos que puedan surgir - ya que los jurídicos tienen los cauces judiciales de resolución-, entiendo que habrá de buscarse el necesario - aunque complejo- equilibrio entre el principio de la unidad de acción exterior del Estado y la misma distribución de competencias entre Estado y Comunidades Autónomas.

Palabras clave: Constitución Española, relaciones internacionales, acción exterior autonómica, Generalidad de Cataluña, diplomacia pública, relaciones consulares, derecho a decidir.

Keywords: Spanish Constitution, international relations, external action of the Autonomous Communities, Generalidad de Cataluña, public diplomacy, consular relations, the right to decide. 